\title{
GHRH excess and blockade in X-LAG syndrome
}

\author{
Adrian F Daly 1,*, Philippe A Lysy 3,*, Céline Desfilles ${ }^{5,6, *}$, Liliya Rostomyan', \\ Amira Mohamed ${ }^{5,6}$, Jean-Hubert Caberg ${ }^{2}$, Veronique Raverot ${ }^{8}$, Emilie Castermans ${ }^{2}$, \\ Etienne Marbaix ${ }^{4}$, Dominique Maiter ${ }^{9}$, Chloe Brunelle ${ }^{3}$, Giampaolo Trivellin ${ }^{7}$, \\ Constantine A Stratakis ${ }^{7}$, Vincent Bours ${ }^{2}$, Christian Raftopoulos ${ }^{10}$, \\ Veronique Beauloye ${ }^{3}$, Anne Barlier ${ }^{5,6}$ and Albert Beckers ${ }^{1}$
}

${ }^{1}$ Department of Endocrinology, Centre Hospitalier Universitaire de Liège, University of Liège, Domaine Universitaire du Sart-Tilman, 4000 Liège, Belgium

${ }^{2}$ Department of Human Genetics, Centre Hospitalier Universitaire de Liège, University of Liège, Domaine Universitaire du Sart-Tilman, 4000 Liège, Belgium

${ }^{3}$ Pediatric Endocrinology Unit, Université Catholique de Louvain, Avenue Hippocrate 10, 1200 Brussels, Belgium

${ }^{4}$ Cliniques Universitaires Saint Luc and Department of Pathology, Université Catholique de Louvain, Avenue Hippocrate 10, 1200 Brussels, Belgium

${ }^{5}$ Laboratory of Molecular Biology, APHM, Hôpital la Conception, 13385, Marseille, France

${ }^{6}$ Aix Marseille Université, CRNS, CRN2M-UMR 7286, 13344, Marseille, France

${ }^{7}$ Section on Endocrinology and Genetics, Program on Developmental Endocrinology and Genetics (PDEGEN) and Pediatric Endocrinology Inter-institute Training Program, Eunice Kennedy Shriver National Institute of Child Health and Human Development (NICHD), National Institutes of Health (NIH), Bethesda, Maryland 20892, USA ${ }^{8}$ Laboratoire d'Hormonologie - CBPE, Groupement Hospitalier Est, Hospices Civils de Lyon, 59 bd Pinel - 69677 Bron Cedex, France

${ }^{9}$ Université Catholique de Louvain, Pole d'endocrinologie, diabete et nutrition (EDIN), Brussels, Belgium

${ }^{10}$ Department of Neurosurgery, Université Catholique de Louvain, Brussels, Belgium

*(A F Daly, P A Lysy and C Desfilles contributed equally to this work)

Correspondence should be addressed to A Beckers Email albert.beckers@chu.ulg.ac.be

\begin{abstract}
X-linked acrogigantism (X-LAG) syndrome is a newly described form of inheritable pituitary gigantism that begins in early childhood and is usually associated with markedly elevated $\mathrm{GH}$ and prolactin secretion by mixed pituitary adenomas/hyperplasia. Microduplications on chromosome Xq26.3 including the GPR101 gene cause X-LAG syndrome. In individual cases random GHRH levels have been elevated. We performed a series of hormonal profiles in a young female sporadic X-LAG syndrome patient and subsequently undertook in vitro studies of primary pituitary tumor culture following neurosurgical resection. The patient demonstrated consistently elevated circulating GHRH levels throughout preoperative testing, which was accompanied by marked $\mathrm{GH}$ and prolactin hypersecretion;

GH demonstrated a paradoxical increase following TRH administration. In vitro, the pituitary cells showed baseline $\mathrm{GH}$ and prolactin release that was further stimulated by $\mathrm{GHRH}$ administration. Co-incubation with GHRH and the GHRH receptor antagonist, acetyl-(D-Arg ${ }^{2}$-GHRH (1-29) amide, blocked the GHRH-induced GH stimulation; the GHRH receptor antagonist alone significantly reduced $\mathrm{GH}$ release. Pasireotide, but not octreotide, inhibited GH secretion. A ghrelin receptor agonist and an inverse agonist led to modest, statistically significant increases and decreases in GH secretion, respectively. GHRH hypersecretion can accompany the pituitary abnormalities seen in X-LAG syndrome. These data suggest that the pathology of X-LAG syndrome may include hypothalamic
\end{abstract}


dysregulation of GHRH secretion, which is in keeping with localization of GPR101 in the hypothalamus. Therapeutic blockade of GHRH secretion could represent a way to target the marked hormonal hypersecretion and overgrowth that characterizes X-LAG syndrome.

\section{Introduction}

Pituitary gigantism is a very recognizable but rare disorder (Rostomyan et al. 2015). Patients with pituitary gigantism develop growth hormone (GH) excess from a pituitary tumor before closure of epiphyseal growth plates. The etiology of pediatric or adolescent pituitary tumors in general, and pituitary gigantism in particular, remains relatively obscure, with about $50 \%$ of cases of the latter having no known genetic cause (Rostomyan et al. 2015). The most frequent known genetic cause is aryl hydrocarbon receptor interacting protein gene (AIP) mutations (Daly \& Beckers 2015). Recently we described a new condition, termed X-linked acrogigantism (X-LAG) syndrome, which is characterized by gigantism occurring during infancy (Trivellin et al. 2014). X-LAG syndrome patients develop pituitary adenomas/hyperplasia and greatly elevated growth hormone (GH) and insulin-like growth factor 1 (IGF1) levels that are usually accompanied by hyperprolactinemia. Unlike other forms of pituitary gigantism due to single gene mutations/deletions, the underlying abnormality in X-LAG syndrome is a microduplication in chromosome Xq26.3 that includes the orphan G-protein coupled receptor (GPCR) gene, GPR101 (Trivellin et al. 2014, Daly et al. 2015).

The clinical features of patients with X-LAG syndrome have been described in detail recently (Beckers et al. 2015). Patients with X-LAG syndrome usually develop pituitary macroadenomas, while some have hyperplasia alone or in conjunction with adenoma. The elevated GH/IGF1 levels are poorly responsive to first-generation somatostatin analogs despite the presence of ample somatostatin subtype 2 receptors (Trivellin et al. 2014, Beckers et al. 2015). Control of growth and hormonal hypersecretion can be achieved by radical resection of the anterior pituitary. Even small amounts of residual tumor are capable of maintaining IGF1 levels in the acromegalic range for many years, thereby necessitating multimodal therapy (Beckers et al. 2015). The GH receptor antagonist, pegvisomant has been a useful option for IGF1 and growth control in a subgroup of cases (Beckers et al. 2015). Even so, the use of multiple treatment modalities does not guarantee control of growth, making X-LAG syndrome a challenging form of pituitary disease (Naves et al. 2015). As clinical experience with X-LAG syndrome during longterm follow-up remains limited, the contribution of modalities like radiotherapy is uncertain. The underlying pathological mechanism driving hyperplasia, adenoma formation, and secretory behavior in X-LAG syndrome is also obscure. To address this issue, we performed a series of hormonal studies and in vitro experiments using primary pituitary culture of an adenoma resected from a young female patient with X-LAG syndrome. The results of these studies strongly suggest an important role for GH-releasing hormone $(\mathrm{GHRH})$ dysregulation in X-LAG syndrome.

\section{Materials and methods}

\section{Case report}

The patient was a 2-year-old female with no family history of growth disorders. Brief details of the patient were reported as part of the original X-LAG syndrome cohort studies (Trivellin et al. 2014, Beckers et al. 2015). She was born at 35.5 weeks gestation and had a birth weight of $2,306 \mathrm{~g}$ and a birth length of $44.5 \mathrm{~cm}$, which were both below the third percentile. Beginning from two months of age she began to grow excessively, exceeding the 97th percentile of her growth charts in terms of length and weight by the ages of 12 and 14 months, respectively. She was diagnosed with marked GH, IGF1 and prolactin excess, and a pituitary MRI demonstrated a large, uniform sellar lesion $(17 \times 8 \times 8 \mathrm{~mm})$ with suprasellar extension. A random level of GHRH was raised, although no potential ectopic sources were identified despite exhaustive imaging, including radionuclide studies (Octreoscan). Treatment with octreotide ( $150 \mu$ g s.c. t.i.d.) and cabergoline $(0.5 \mathrm{mg} /$ week) was initiated, but IGF1 levels remained consistently elevated. She was diagnosed with X-LAG syndrome based on an array CGH study that showed a microduplication on chromosome Xq26.3 that was confirmed by fluorescent in situ hybridization studies on peripheral blood leukocytes. As chronic treatment with somatostatin analogs and dopamine agonists for 12 months had no effect on the patient's excessive growth

Published by Bioscientifica Ltd 
and her pituitary lesion began impinging on the optic chiasm, she was referred for neurosurgical treatment.

At transsphenoidal surgery, a gross total resection of the anterior pituitary was performed. Histology revealed a densely cellular tissue specimen comprised of cords of polymorphic cells with abundant cytoplasm (some acidophilic, some chromophobic) and rounded nuclei. Some nuclear atypia was seen, as were some mitotic figures. Small calcifications were identified but no necrotic foci were seen. The pathological findings are shown in Fig. 1. Silver staining demonstrated widespread pituitary hyperplasia with widening of the pituitary acini, which was accompanied by focal loss of acinar structure in specific regions indicating adenoma formation. Immunohistochemistry revealed widespread positivity for GH (Biomeda, Foster City, CA, USA) and prolactin (DakoCytomation, Heverlee, Belgium) throughout the lesion. Staining for Adrenocorticotropin and Thyrotropin (both DakoCytomation) was limited to the periphery of the resected tissue and rare cells disseminated within the lesion (LH staining was very rare and Follicle-stimulating hormone staining was absent (DakoCytomation)). Nuclear positivity for p53 (DO-7 clone, BioCare Medical, Concord, CA, USA) was focally intense in some cells within the lesion and the Ki67 index (MIB-1, DakoCytomation) was elevated at 5\%. CAM 5.2 (Becton-Dickinson, Erdembodegem, Belgium) staining revealed cytoplasmic peri-nuclea, dotlike positivity patterns. The overall pathological result was determined to be a combination of extensive $\mathrm{GH} /$ prolactin positive hyperplasia of the anterior pituitary with an atypical

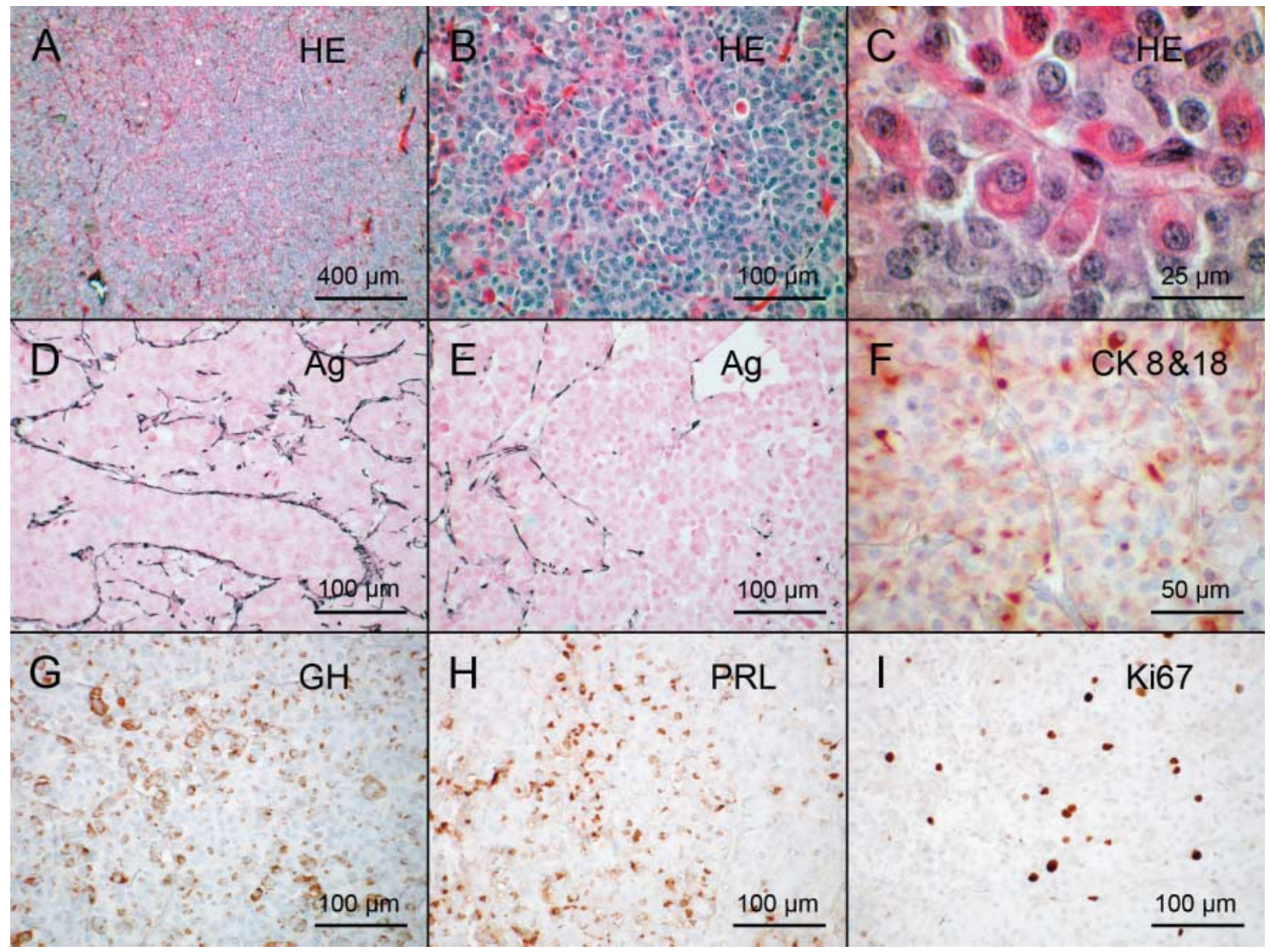

\section{Figure 1}

Histological and immunohistochemical appearance of the pituitary lesion. Histological sections were stained with hematoxylin and eosin ( $A, B$ and $C$ ) and with silver to highlight the reticulinic fibres (D and $E$ ), or immunostained with the CAM 5.2 monoclonal mouse antibody against cytokeratins 8 and $18(\mathrm{~F})$, with polyclonal rabbit antibody against growth hormone $(\mathrm{G})$ or against prolactin $(\mathrm{H})$, or with the MIB-1 mouse monoclonal antibody against Ki67 (I). Hematoxylin and eosin-stained sections ( $A, B$ and $C$ ) show the abundance of acidophilic somatotroph cells. Argyrophilic staining show that reticulinic fibres are still present in most parts of the lesion (D), indicating its hyperplastic nature, but tend to disappear in areas $(E)$, suggesting development of an adenoma within the hyperplastic tissue. Pituitary cells contain cytokeratin filaments, most often diffusely distributed in the cytoplasm but concentrated in a perinuclear dot in a few cells $(F)$. Many cells contain growth hormone $(G)$ or prolactin $(H)$. About $5 \%$ of pituitary cells are proliferating as indicated by Ki67 immunostaining (I). Bars correspond to $400 \mu \mathrm{m}$ in $\mathrm{A}$, to $100 \mu \mathrm{m}$ in $\mathrm{B}, \mathrm{D}, \mathrm{E}, \mathrm{G}$, $\mathrm{H}, \mathrm{I}$, to $50 \mu \mathrm{m}$ in $\mathrm{F}$, and to $25 \mu \mathrm{m}$ in $\mathrm{C}$.

Published by Bioscientifica Ltd. 
mixed GH/ prolactin adenoma. Staining for somatostatin receptors subtypes 2 and 5 was present at moderate to high levels.

Postoperatively the patient had permanent cortisol and thyroid deficiencies and diabetes insipidus, which were all replaced. During 10 months of follow-up her GH levels were between 0.9 and $1.4 \mathrm{ng} / \mathrm{ml}$ (normal: $<4 \mathrm{ng} / \mathrm{ml}$ ), while her IGF1 levels were near to or above the upper limit of the normal range for her age/sex (160.7-180.4 ng/ml; normal range: $51-170 \mathrm{ng} / \mathrm{ml})$. Her height (116.5 cm; + 3 SDS) and weight ( $23.5 \mathrm{~kg} ;+2.4 \mathrm{SDS})$ remain elevated 10 months postoperatively.

\section{Cell culture}

A surgical sample of the human pituitary adenoma in DMEM was dissociated mechanically and enzymatically as described previously (Jaquet et al. 1985). A sample of the medium in which this preparation was performed was retained for hormonal analysis. A total of 50000 tumor cells per well were plated in 24 well plates coated with extracellular matrix from bovine endothelial corneal cells required for cell adhesion as previously described (Jaquet et al. 1985, Barlier et al. 1999, Saveanu et al. 2002, Jaquet et al. 2005). The total incubation times were short and have been established not to influence cell number/viability in the setting of pituitary somatotrope primary cultures (Jaquet et al. 1985, Barlier et al. 1999, Saveanu et al. 2002, Jaquet et al. 2005), hence hormone levels were not normalized to the number of living cells. The cells were cultured in DMEM depleted of L-valine (D-valine-DMEM) to block fibroblast proliferation, supplemented with $1 \%$ FCS, penicillin $(100 \mathrm{U} / \mathrm{ml})$, streptomycin $(100 \mu \mathrm{g} / \mathrm{ml})$, and glutamine $(100 \mathrm{U} / \mathrm{ml})$ at $37^{\circ} \mathrm{C}$ in a watersaturated atmosphere containing $7 \% \mathrm{CO}_{2}$. After $48 \mathrm{~h}$, culture medium was changed to D-valine DMEM containing 1\% Insulin Transferin Selenium and 1\% FCS for another $48 \mathrm{~h}$. Cells were incubated with drugs at a range of concentrations $\left(10^{-12}-10^{-7} \mathrm{~mol} / \mathrm{l}\right)$ for $16 \mathrm{~h}$ (overnight). After these initial studies, the cells were washed three times before undergoing GHRH and GHRH antagonist studies. All experiments were performed in triplicate. The medium was collected and stored frozen for hormonal assays.

\section{Pharmacological compounds}

The SSAs, octreotide, and pasireotide were kindly provided by Novartis. Forskolin was obtained from Sigma-Aldrich. Cabergoline was obtained from Pfizer (Pharmacia \& Upjohn, Kalamazoo, MI, USA) and
MK-0677 (ghrelin analog) was obtained from Europeptide (Argenteuil, France); MSP (ghrelin receptor-GHS-R inverse agonist) came from Polypeptide Laboratories (Strasbourg, France). The GHRH receptor antagonist, acetyl-(D-Arg ${ }^{2}$ )GHRH (1-29) amide, and gonadotropin-releasing hormone $(\mathrm{GnRH})_{1-5}$ were obtained from Bachem (Europe). Peptides used for dynamic hormonal stimulation studies in vivo, such as GnRH, were obtained as HRF-Ayerst (Elsene, Belgium).

\section{Hormonal assays}

GH secretion by the primary culture cells was quantified using the AlphaLisa human growth hormone GH kit (Perkin Elmer, Waltham, MA, USA). For that assay, the intra-assay coefficient of variation (CV) is $4.9-5.4 \%$ and the inter-assay CV is $6.1-6.9 \%$ over the concentration range studied. Prolactin levels were measured in culture medium using a commercial IRMA kit (Prolactin (PRL) IRMA Kit-Beckman Coulter Immunotech, Marseille, France). Human GHRH concentrations in plasma were measured using an in-house double-antibody radio-immunoassay as described previously and using a standard solution of Stimu-GH $50 \mu \mathrm{g}$ (Ferring, Aalst, Belgium), and the matrix was non-used culture medium (Girard et al. 1987).

\section{Statistical analysis}

Data are expressed as mean \pm s.E.M. The statistical tests used were the non-parametric paired Wilcoxon and non-paired Mann-Whitney tests. Significance was set at $P \leq 0.05$.

\section{Results}

\section{Dynamic hormone profiles}

Preoperatively a series of dynamic pituitary hormone tests were performed, including a 180 min test for GH, PRL, and GHRH pulsatility, a GnRH test ( $25 \mu \mathrm{g}$ i.v. GnRH) to study PRL, GH, and GHRH $(0,15,30$, and $90 \mathrm{~min})$, and a thyrotropin-releasing hormone (TRH) test $(125 \mu \mathrm{g}$ i.v.) with measurements of PRL, GH, and GHRH $(0,15,30$, and $90 \mathrm{~min}$ ). These were all performed in the immediate preoperative period after sufficient washout of octreotide ( $>48 \mathrm{~h}$ ) and cabergoline (4 weeks). The pulsatility study (Fig. 2A) demonstrated markedly raised levels of GH and PRL throughout, and all GHRH levels were elevated at all study time points. Fluctuations in elevated GHRH levels also occurred, and these were partially but not completely in phase with alterations in GH. While the elevated PRL

Published by Bioscientifica Ltd. 


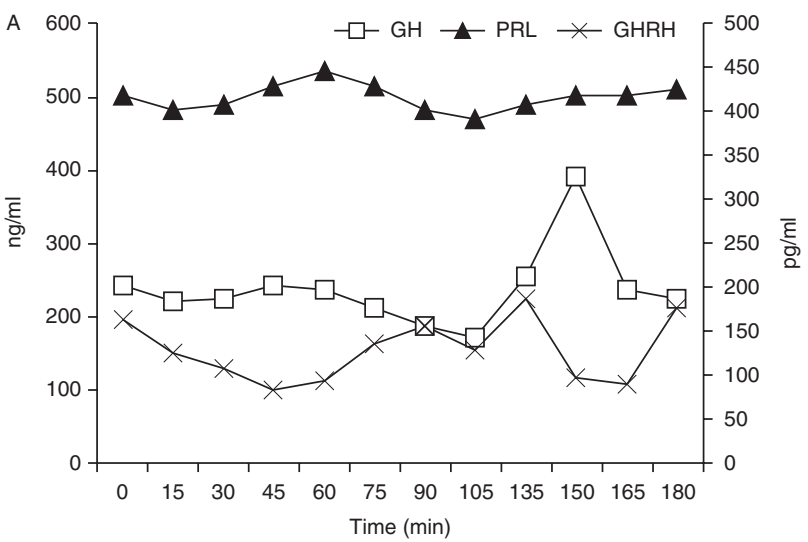

baseline level of GH (212 ng/ml) decreased to $50 \mathrm{ng} / \mathrm{ml}$. Again, the GHRH level was also elevated at baseline $(138 \mathrm{pg} / \mathrm{ml})$ and remained elevated throughout.
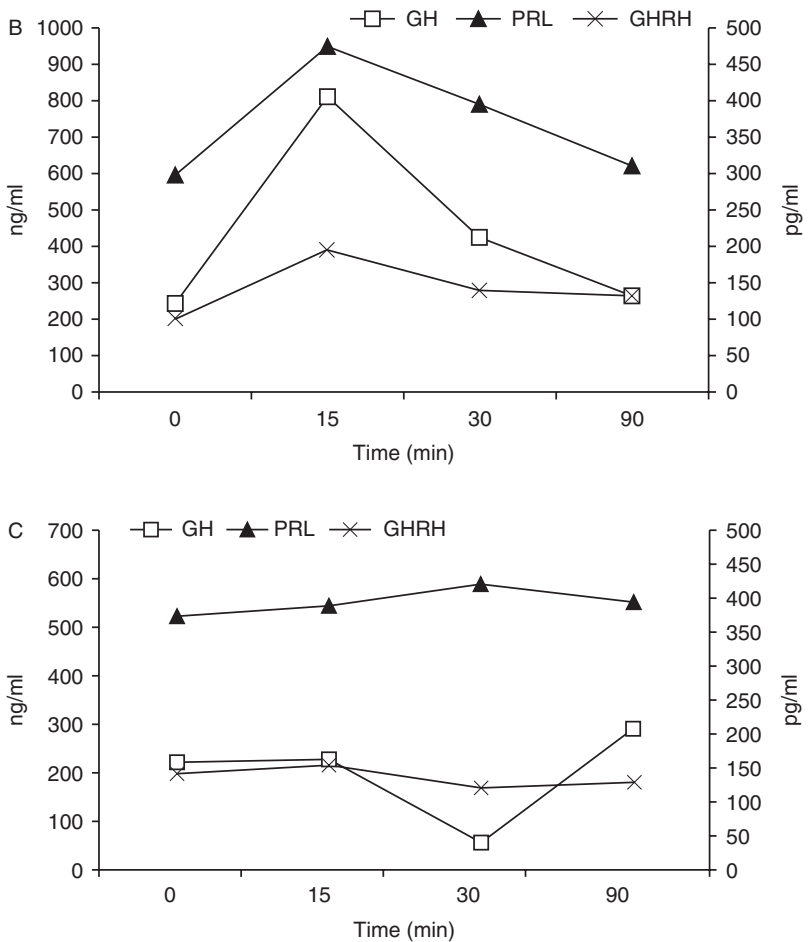

\section{Cell culture experiments}

In the medium used for cell expansion before pharmacological incubation studies, the GHRH concentration was $0.3 \mathrm{ng} / 50000$ cells. In 1\% FCS and ITS, the $24 \mathrm{~h}$ secretion for 50000 cells was $40 \mathrm{ng} / \mathrm{ml}$ for $\mathrm{GH}$ and $300 \mathrm{ng} / \mathrm{ml}$ for PRL, indicating that the tumor cells were actively producing hormone. The GHRH concentration was below the lower limit of the assay $(<62 \mathrm{pg} / \mathrm{ml})$ under these same experimental conditions.

As shown in Fig. 3A, basal GH secretion was further stimulated by incubation with GHRH, reaching a peak at a GHRH concentration of $10^{-10} \mathrm{M}(+41 \pm 0.4 \%)$. In contrast, the putative GPR101 agonist, $\mathrm{GnRH}_{1-5}$, had little effect on GH across the dose range studied $(+15 \pm$ $1.5 \%$ at $\left.10^{-10} \mathrm{M}\right)$. PRL secretion was slightly stimulated by GHRH $\left(+11 \pm 0.4 \%\right.$ at $\left.10^{-8} \mathrm{M}\right)$. $\mathrm{GnRH}_{1-5}$ did not stimulate PRL release (Fig. 3B).

When tumor cells were incubated with the SSTR2specific somatostatin analog, octreotide, no inhibition in GH secretion was seen, while the PRL decrease was $-26 \pm 0.03 \%$ at $10^{-9} \mathrm{M}$ (Fig. 3C). In contrast, following incubation with pasireotide, a multi-somatostatin receptor agonist, a decrease in GH secretion was seen, reaching a maximum inhibition at $10^{-8} \mathrm{M}(-18 \pm 0.6 \%$; pasireotide had no effect on PRL secretion in these tumor cells (Fig. 3D)). The $\mathrm{D}_{2}$-receptor agonist, cabergoline, displayed stronger inhibition than either somatostatin analog on GH secretion ( $-32 \pm 0.8 \%$ at $10^{-8} \mathrm{M}$; Fig. $\left.3 \mathrm{C}\right)$, but the inhibition of PRL was less ( $-15 \pm 0.04 \%$; Fig. 3D)).

We then studied the effect of a GHRH receptor

Figure 2 (PRL), and GHRH levels were seen throughout an extended testing period of $180 \mathrm{~min}(\mathrm{~A})$. GH levels are seen to peak at $150 \mathrm{~min}$ after an earlier GHRH rise between 105 and $135 \mathrm{~min}$. A thyrotrophin-releasing hormone test induced an immediate and marked increase in GH levels, and GHRH remained largely unchanged (B). Gonadotropin-releasing hormone administration led to suppression of $\mathrm{GH}$ levels at $30 \mathrm{~min}$, whereas $\mathrm{GHRH}$ levels remained unaltered and prolactin rose mildly (C). GH and PRL are measured in $\mathrm{ng} / \mathrm{ml}$; GHRH is measured in $\mathrm{pg} / \mathrm{ml}$.

levels varied by $< \pm 7 \%$ from baseline throughout the study, changes in GH levels were more marked $(-23.6 \%$ to $+61.5 \%)$.

A TRH test (Fig. 2B) led to a paradoxical rise in GH that was accompanied by the expected rise in PRL. Following GnRH administration (Fig. 2C), the grossly elevated antagonist, acetyl-(D-Arg ${ }^{2}$ )-GHRH (1-29) amide, on GH and PRL secretion (Fig. 4). There was an initial stimulatory effect of the GHRH receptor antagonist on GH secretion at $10^{-13}$ to $10^{-11} \mathrm{M}(+18 \pm 0.8 \%$ and $+13 \pm 1.9 \%$, respectively). This was followed by a dose-dependent inhibition of GH secretion, reducing GH secretion to approximately $-34 \pm 1.9 \%$ of controls at the highest GHRH receptor antagonist dose studied (Fig. 4A). Interestingly, incubation with the GHRH receptor antagonist also markedly decreased PRL secretion, $-73 \pm 0.1 \%$ at a concentration of $10^{-8} \mathrm{M}$ (Fig. 4B). Co-incubation of GHRH $\left(10^{-10} \mathrm{M}\right)$ with the GHRH antagonist led to complete abolition of the GH and PRL responses to GHRH antagonist (Fig. 4A and B). 

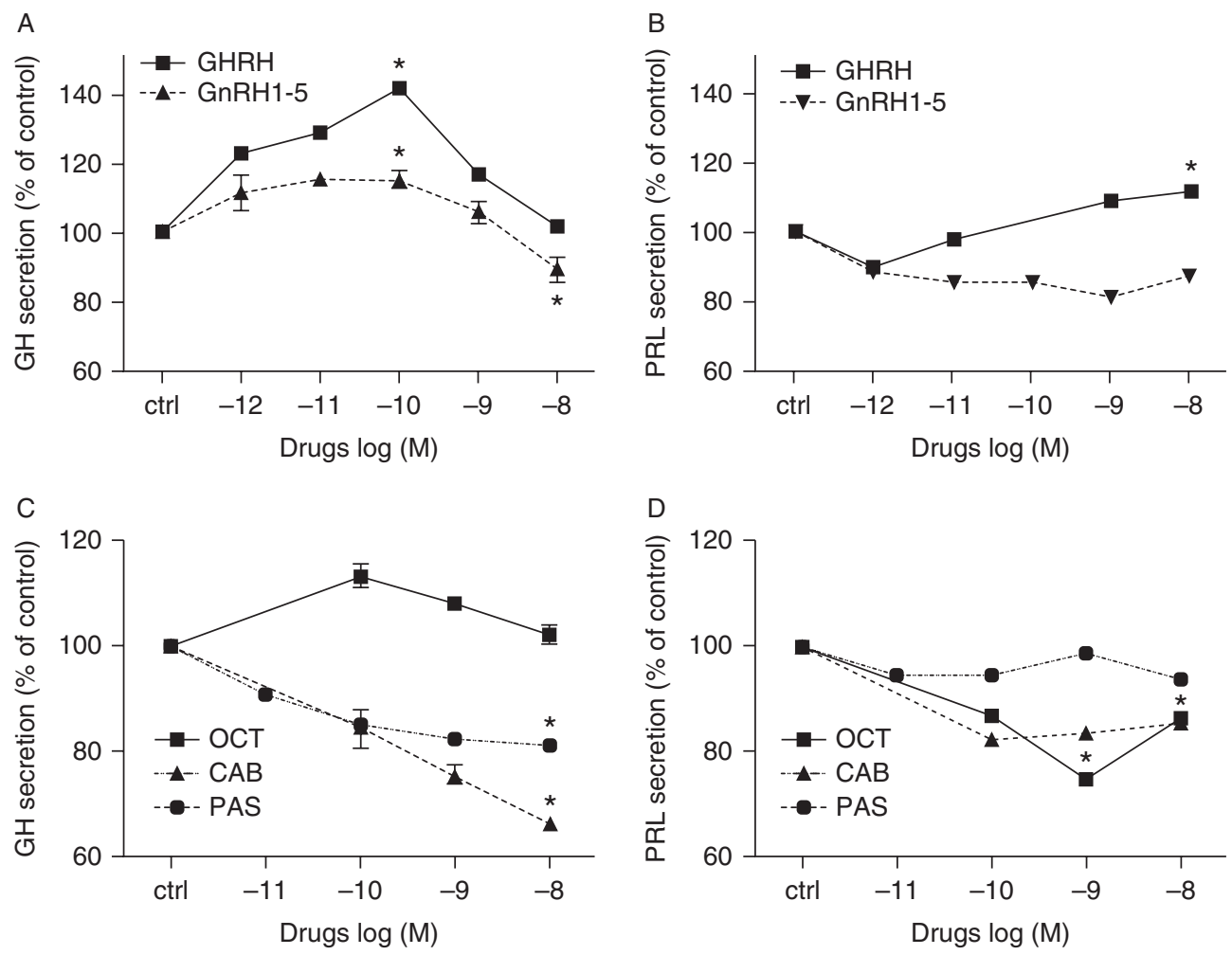

Figure 3

The in vitro dose-effect on $\mathrm{GH}$ ( $\mathrm{A}$ and $\mathrm{C}$ ) and prolactin (PRL) (B and $\mathrm{D}$ ) secretion in somatotroph cells after overnight incubation with $(A, B) G H R H$, $\mathrm{GnRH}_{1-5}$, (C and $\mathrm{D}$ ) octreotide (OCT), cabergoline (CAB), or pasireotide

Figure 5 shows the effects of incubation with a ghrelin analog, MK-0677, and the inverse agonist of the ghrelin receptor, MSP. MK-0677 had a minor stimulatory effect on GH secretion as compared with control $(+15 \pm 0.5 \%)$ and no effect on PRL secretion. MSP did, however, decrease GH and PRL secretion by $-24 \% \pm 0.3 \%$ and $-12 \pm 0.08 \%$, respectively, as compared with controls.

\section{Discussion}

$\mathrm{X}$-LAG syndrome is a novel condition due to microduplications on chromosome Xq26.3 involving the orphan GPCR, GPR101 (Trivellin et al. 2014). This condition leads to a dramatic phenotype of early childhood onset gigantism due to large mixed GH- and PRL-secreting pituitary adenomas and/or hyperplasia (Beckers et al. 2015). A progression from normal tissue through hyperplasia to adenoma has been seen in resected tumor tissue (Trivellin et al. 2014). The pituitary pathology progression suggests that while there may be an underlying abnormality (such as GHRH secretion) causing the hyperplasia, second hits may be involved in

(PAS). The results are expressed as the mean percentage of PRL or GH change compared to the values of control wells (ctrl). ${ }^{\star} P<0.05$.

leading to the adenoma formation; this remains to be investigated fully in X-LAG syndrome. Usually both GH and PRL secretion are highly elevated at diagnosis. We also reported previously that while GHRH staining was absent in tumors from X-LAG syndrome patients, abundant GHRH-R was seen in both hyperplastic and adenomatous regions (Trivellin et al. 2014, Beckers et al. 2015). The X-LAG syndrome cohort and literature cases with an identical phenotype include cases with individually high circulating GHRH levels in the absence of a peripheral source such as a neuroendocrine tumor. As those cases were largely retrospective, more detailed hormonal and tumoral studies were not possible. The current patient is the youngest case diagnosed in the University of Liège-NIH collaborative cohort, which includes 22 cases at the time of writing. Subsequent to the diagnosis of X-LAG syndrome, a single elevated GHRH was noted during the patient's clinical workup. In the current study, during the preoperative period we found increased GHRH levels at all time points, ranging between 100 and $200 \mathrm{pg} / \mathrm{ml}$. These moderately elevated GHRH levels were seen against a backdrop of markedly

Published by Bioscientifica Ltd. 

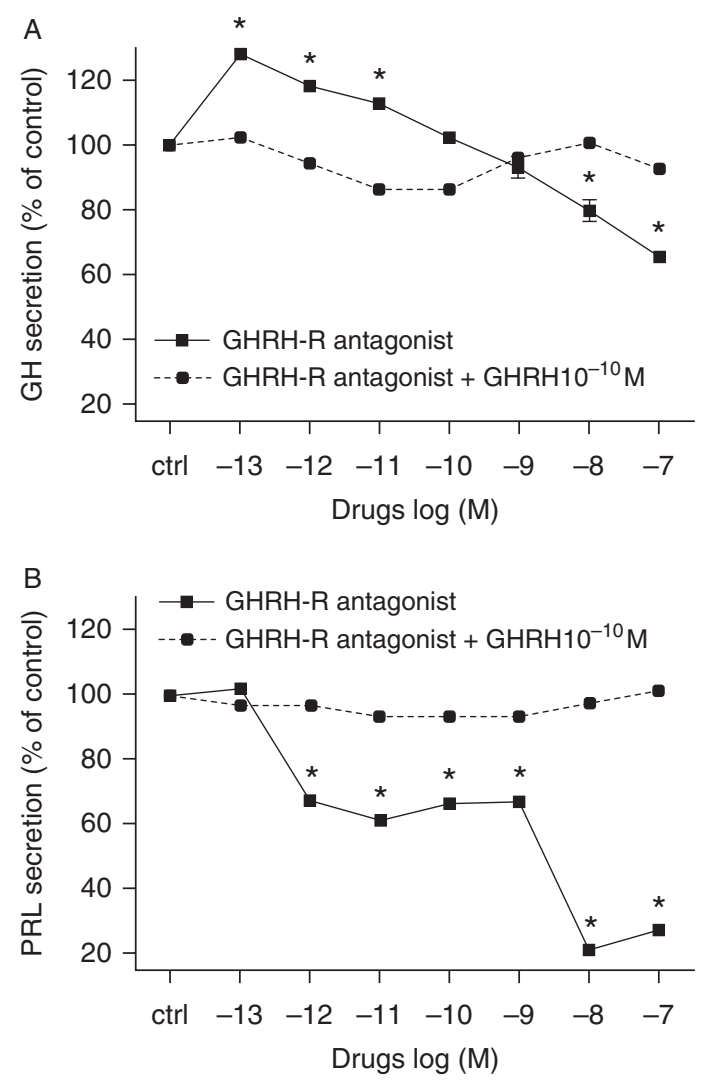

Figure 4

The in vitro dose-effect on GH (A) and prolactin (PRL) (B) secretion in somatotroph cells after overnight incubation with GHRH-R antagonist, with or without $\mathrm{GHRH}$ at $10^{-10} \mathrm{M}$. The results are expressed as the mean percentage of PRL or GH change compared to the values of control wells (ctrl). ${ }^{*} P<0.05$.

increased circulating GH and PRL concentrations in excess of 200 and $500 \mathrm{ng} / \mathrm{ml}$, respectively, at baseline. A pulsatility study showed elevations in GHRH, GH, and PRL throughout the $180 \mathrm{~min}$ of the study. One peak of GHRH secretion was captured and was seemingly accompanied by a concomitant peak in GH but not PRL secretion. The elevated GHRH was not markedly altered by TRH or GnRH administration. While a longer testing period would have provided more information on GHRH patterns, this was not feasible due to the young age of the patient. No peripheral source of GHRH was found (in keeping with other X-LAG syndrome cases), indicating that GHRH hypersecretion could be an intrinsic part of the etiology of X-LAG syndrome, at least in some patients.

The source of the chronically elevated circulating GHRH is likely to be central, based on a number of lines of evidence. As noted above, no peripheral sources were seen following exhaustive imaging studies. Also the GHRH level was moderately elevated and was not consistent with the magnitude of the GHRH elevation that is encountered typically in ectopic GHRH hypersecretion from a neuroendocrine tumor. The pathology of pituitary disease in this and other cases of X-LAG syndrome bears strong resemblance to that seen in other settings of GHRH excess. As noted previously, peripheral GHRH hypersecretion from a neuroendocrine tumor is accompanied by either pituitary somatotrope hyperplasia or mixed GH- and PRL-secreting adenomas (Borson-Chazot et al. 2012). Central GHRH hypersecretion from hypothalamic gangliocytomas leads to pituitary adenoma and acromegaly (Asa et al. 1984). Hypersecretion of GHRH in mice transgenic for the human GHRH gene leads to the development of early and massive pituitary hyperplasia (somatotrope, mammotrope, and somatomammotrope) (Mayo et al. 1988); similar extensive hyperplasia accompanied adenoma formation in the current case and in other X-LAG syndrome patients (Trivellin et al. 2014). Furthermore, in older transgenic
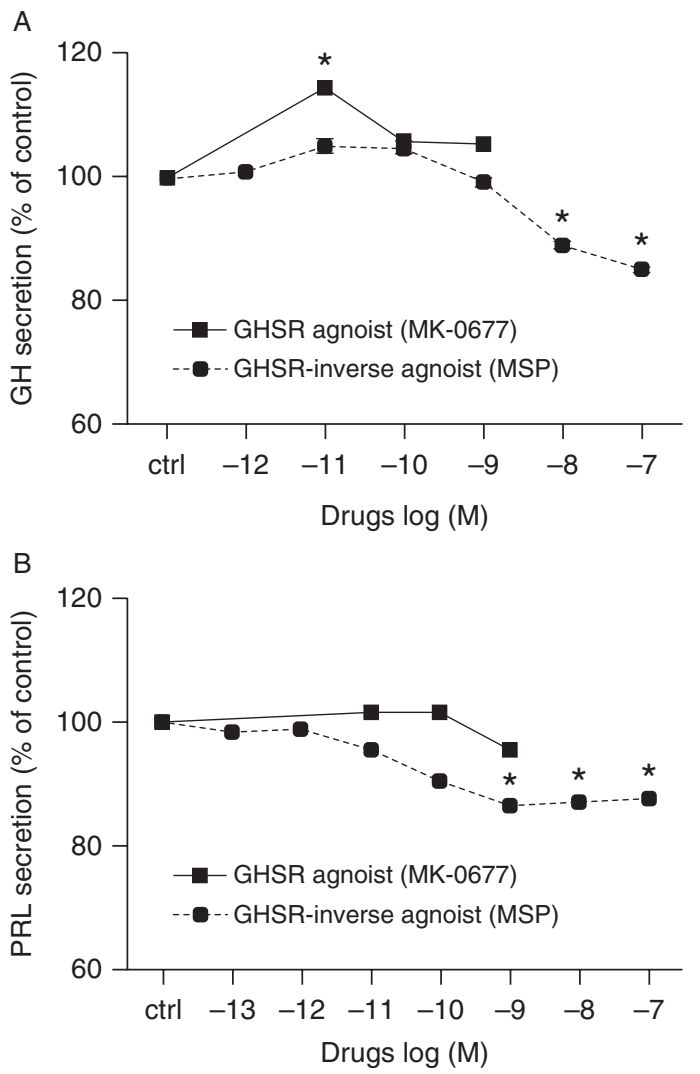

Figure 5

The in vitro dose-effect on $\mathrm{GH}(\mathrm{A})$ and prolactin (PRL) (B) secretion in somatotroph cells after overnight incubation with GHSR agonist (MK 0677) or GHSR-inverse agonist (MSP). The results are expressed as the mean percentage of PRL or GH change compared to the values of control wells (ctrl). ${ }^{\star} P<0.05$.

Published by Bioscientifica Ltd. 
mice, chronic GHRH hypersecretion leads to pituitary adenoma formation, predominantly with GH and PRL staining (Asa et al. 1992). Taken together, the sum effect of chronic GHRH hypersecretion on the pituitary is somatotrope, mammotrope, and somatomammotrope hyperplasia and/or mixed GH- and PRL-secreting adenomas, which is the picture seen in this and other cases of X-LAG syndrome. This strongly suggests that the central GHRH hypersecretion seen in the current case may explain the pituitary histological changes that occur in X-LAG syndrome.

One further area that requires more investigation is the GHRH receptor activity in this and other pituitary tumors. We found that not only did a GHRH receptor antagonist block GHRH-related stimulation of GH, but the GHRH receptor antagonist itself was capable of reducing basal GH secretion. This suggests that the cells may have some intrinsic GHRH receptor related GH secretion at baseline, which requires further study, as tumors in patients with X-LAG syndrome express significant numbers of GHRH receptors (Trivellin et al. 2014, Beckers et al. 2015, Naves et al. 2015). Indeed a whole range of studies into the behavior of the pituitary in X-LAG syndrome may help elucidate some of the specific features of somatotrope behavior in response to GHRH in early life (fetal/ neonatal), as compared with the adult life (Collins et al. 1996, Torronteras et al. 1997, 2012).

Further support for a role for GHRH hypersecretion in $\mathrm{X}$-LAG syndrome comes from the in vitro pituitary culture data, which are the first results to be reported in a tumor from a known case of X-LAG syndrome. These results confirm basal GH and PRL hypersecretion, which was further stimulated by GHRH co-incubation. Crucially, the addition of the GHRH antagonist acetyl-(D-Arg ${ }^{2}$ )-GHRH (1-29) was able to reduce basal and stimulated GH and PRL secretion in a dose-dependent manner. Co-incubation of acetyl-(D-Arg ${ }^{2}$ )-GHRH (1-29) with GHRH abolished the stimulatory effect of GHRH itself. This combination of findings suggests that clinical benefit could be derived from pharmacological treatment with GHRH antagonists in X-LAG syndrome. Previous work in normal volunteers and in a patient with ectopic tumoral GHRH hypersecretion shows that such an approach with acetyl-(D-Arg ${ }^{2}$ )GHRH (1-29) and other GHRH analogs is clinically feasible (Jaffe et al. 1993, 1997, Kovacs et al. 1997). Newer GHRH antagonists are being tested clinically in other settings but could also have applications in X-LAG syndrome (Kovacs et al. 2010, Szalontay et al. 2014).

Postoperatively the GHRH was tested at a single time point (lengthy dynamic testing was declined) and found to be in the normal range. We cannot rule out that GHRH remains intermittently elevated at this time. This normal GHRH level also could be interpreted as pointing to the resected tissue being a source of the GHRH secretion. However, immunohistochemical studies of this and other X-LAG syndrome cases are negative for GHRH (Trivellin et al. 2014, Beckers et al. 2015). In addition, RNA studies of tumor from multiple X-LAG syndrome cases show no GHRH expression (AF Daly, G Trivellin, L Palmeira, A Beckers \& CA Stratakis, unpublished observations). These two findings argue strongly against the tumor itself being the GHRH source. Following surgery the patient exhibited deficiency in thyroid and adrenal axes, plus diabetes insipidus, indicating significant pituitary stalk impairment. Despite this, the IGF1 secretion has remained at or above the upper limit of normal. Taken together, this suggests that the patient might have a small adenomatous remnant that is autonomously producing $\mathrm{GH}$. Such small tumor remnants in X-LAG syndrome have led to chronic GH hypersecretion over decades in affected patients, requiring long-term medical treatment (Trivellin et al. 2014, Beckers et al. 2015). We suggest that tumor resection led to pituitary stalk impairment that prevented normal flow of hypothalamic factors - including GHRH - to the pituitary and into the circulation via the venous channels. This could explain the picture of significant GH/IGF1 secretion in the absence of elevated GHRH as had been present before surgery. Alternatively, the pituitary tissue itself could have contained a factor that led to feedback dysregulation of hypothalamic GHRH, and surgical resection could have removed this abnormality. This remains speculative but cannot be completely discounted in the setting of tumoral GPR101 overexpression, for which no regulators, ligands, or physiological/ pharmacological modulators are yet known.

We also studied a number of other stimulatory and inhibitory factors. We previously reported poor clinical responses to SSTR2-specific somatostatin analogs in X-LAG syndrome, despite strong immunohistochemical staining for SSTR2 in tumor samples (Trivellin et al. 2014, Beckers et al. 2015, Naves et al. 2015). In keeping with this, octreotide had no inhibitory effect on GH or PRL in the $\mathrm{X}$-LAG syndrome pituitary cell culture, which supports the poor response to octreotide during chronic treatment in this case. Pasireotide had a small inhibitory effect on GH secretion, which suggests that some clinical benefit might be obtained in X-LAG syndrome via its binding at SSTR5 and SSTR3, as these receptor types are expressed in X-LAG syndrome tumor tissue (Beckers et al. 2015). The $\mathrm{GnRH}_{1-5}$ fragment was suggested elsewhere to potentially act as a

Published by Bioscientifica Ltd. 
ligand for GPR101, the orphan GPCR overexpressed due to the Xq26.3 microduplication causing X-LAG syndrome (Cho-Clark et al. 2014, 2015). In our study, $\mathrm{GnRH}_{1-5}$ had only a minor stimulatory effect on GH at lower doses and a small inhibitory effect at the highest dose $10^{-8} \mathrm{M}$. The lack of a marked effect in this tissue culture might be due to inter-tissue differences, as much of the previous data on $\mathrm{GnRH}_{1-5}$ was generated in an endometrial cell line. As some patients with X-LAG syndrome exhibit increased appetite in conjunction with their gigantism, we were interested in studying the effects of ghrelin in the tumor tissue. Ghrelin agonism itself had a minor stimulatory effect on GH secretion, while a ghrelin receptor inverse agonist inhibited GH secretion at $10^{-8}$ and $10^{-7} \mathrm{M}$. These results suggest that patients with X-LAG syndrome may have GH dysregulation across various control pathways, although specific studies are needed.

In conclusion, this study provides new evidence that central GHRH dysregulation is a feature of the pituitary pathology and gigantism seen in X-LAG syndrome. It may be that chronic GHRH hypersecretion from the hypothalamus in X-LAG syndrome contributes to the pituitary pathology of mixed GH/PRL positive hyperplasia and adenoma, which mirrors that seen in other experimental and clinical settings with GHRH excess. Inhibition of GH and PRL secretion from cell culture in X-LAG syndrome using a GHRH antagonist suggests that the challenging clinical management of X-LAG syndrome could be improved by targeting GHRH inhibition.

\section{Declaration of interest}

The authors declare that there is no conflict of interest that could be perceived as prejudicing the impartiality of the research reported.

\section{Funding}

This research was supported by funding from the Fonds d'Investissement de Recherche Scientifique (FIRS) of the Centre Hospitalier Universitaire de Liège.

\section{Acknowledgements}

Tissue used in this publication was provided by the BioBank of the Institut Roi Albert II of the Cliniques Universitaires Saint-Luc, Brussels, Belgium, project CDCUCLR23.

\section{References}

Asa S, Scheithauer BW, Bilbao JM, Horvath E, Ryan N, Kovacs K, Randall RV, Laws ER Jr, Singer W, Linfoot JA et al. 1984 A case for hypothalamic acromegaly: a clinicopathological study of six patients with hypothalamic gangliocytomas producing growth hormone-releasing factor. Journal of Clinical Endocrinology and Metabolism 58 796-803. (doi:10.1210/jcem-58-5-796)

Asa SL, Kovacs K, Stefaneanu L, Horvath E, Billestrup N, GonzalezManchon C \& Vale W 1992 Pituitary adenomas in mice transgenic for growth hormone-releasing hormone. Endocrinology 131 2083-2089.

Barlier A, Zamora AJ, Grino M, Gunz G, Pellegrini-Bouiller I, MorangeRamos I, Figarella-Branger D, Dufour H, Jaquet P \& Enjalbert A 1999 Expression of functional growth hormone secretagogue receptors in human pituitary adenomas: polymerase chain reaction, triple in-situ hybridization and cell culture studies. Journal of Neuroendocrinology $\mathbf{1 1}$ 491-502. (doi:10.1046/j.1365-2826.1999.00351.x)

Beckers A, Lodish MB, Trivellin G, Rostomyan L, Lee M, Faucz FR, Yuan B, Choong CS, Caberg JH, Verrua E et al. 2015 X-linked acrogigantism syndrome: clinical profile and therapeutic responses. Endocrine-Related Cancer 22 353-367. (doi:10.1530/ERC-15-0038)

Borson-Chazot F, Garby L, Raverot G, Claustrat F, Raverot V, Sassolas G \& GTE group 2012 Acromegaly induced by ectopic secretion of GHRH: a review 30 years after GHRH discovery. Annales D'Endocrinologiee $\mathbf{7 3}$ 497-502. (doi:10.1016/j.ando.2012.09.004)

Cho-Clark M, Larco DO, Semsarzadeh NN, Vasta F, Mani SK \& Wu TJ 2014 GnRH-(1-5) transactivates EGFR in Ishikawa human endometrial cells via an orphan G protein-coupled receptor. Molecular Endocrinology 28 80-98. (doi:10.1210/me.2013-1203)

Cho-Clark M, Larco DO, Zahn BR, Mani SK \& Wu TJ 2015 GnRH-(1-5) activates matrix metallopeptidase-9 to release epidermal growth factor and promote cellular invasion. Molecular and Cellular Endocrinology $\mathbf{4 1 5}$ 114-125. (doi:10.1016/j.mce.2015.08.010)

Collins BJ, Szabo M \& Cuttler L 1996 Differential desensitization response of the neonatal and adult rat somatotroph to growth hormonereleasing hormone and phorbol ester. Molecular and Cellular Endocrinology 117 75-81. (doi:10.1016/0303-7207(95)03731-4)

Daly AF \& Beckers A 2015 Familial isolated pituitary adenomas (FIPA) and mutations in the aryl hydrocarbon receptor interacting protein (AIP) gene. Endocrinology and Metabolism Clinics of North America 44 19-25. (doi:10.1016/j.ecl.2014.10.002)

Daly AF, Trivellin G \& Stratakis CA 2015 Gigantism, acromegaly, and GPR101 mutations. New England Journal of Medicine 3721265.

Girard P, Cohen R, Sassolas G, Harthe C, Cabrera P \& Boissel JP 1987 Pharmacokinetics of human growth hormone releasing factor (hGRF-44 NH2) in normal men after intravenous administration of a large range of doses. European Journal of Clinical Pharmacology 32 507-513. (doi:10.1007/BF00637679)

Jaffe CA, Friberg RD \& Barkan AL 1993 Suppression of growth hormone (GH) secretion by a selective GH-releasing hormone (GHRH) antagonist, direct evidence for involvement of endogenous GHRH in the generation of GH pulses. Journal of Clinical Investigation 92 695-701. (doi:10.1172/JCI116639)

Jaffe CA, DeMott-Friberg R, Frohman LA \& Barkan AL 1997 Suppression of growth hormone (GH) hypersecretion due to ectopic GH-releasing hormone (GHRH) by a selective GHRH antagonist. Journal of Clinical Endocrinology and Metabolism 82 634-637.

Jaquet P, Gunz G \& Grisoli F 1985 Hormonal regulation of Prolactin release by human prolactinoma cells cultured in serum-free conditions. Hormone Research 22 153-163. (doi:10.1159/000180089)

Jaquet P, Gunz G, Saveanu A, Dufour H, Taylor J, Dong J, Kim S, Moreau JP, Enjalbert A \& Culler MD 2005 Efficacy of chimeric molecules directed towards multiple somatostatin and dopamine receptors on inhibition of GH and prolactin secretion from GH-secreting pituitary adenomas classified as partially responsive to somatostatin analog therapy. European Journal of Endocrinology/European Federation of Endocrine Societies 153 135-141. (doi:10.1530/eje.1.01950)

Kovacs M, Kineman RD, Schally AV, Zarandi M, Groot K \& Frohman LA 1997 Effects of antagonists of growth hormone-releasing hormone (GHRH) on GH and insulin-like growth factor I levels in transgenic

Published by Bioscientifica Ltd. 
mice overexpressing the human GHRH gene, an animal model of acromegaly. Endocrinology 138 4536-4542.

Kovacs M, Schally AV, Hohla F, Rick FG, Pozsgai E, Szalontay L, Varga JL \& Zarandi M 2010 A correlation of endocrine and anticancer effects of some antagonists of GHRH. Peptides 31 1839-1846. (doi:10.1016/j. peptides.2010.07.006)

Mayo KE, Hammer RE, Swanson LW, Brinster RL, Rosenfeld MG \& Evans RM 1988 Dramatic pituitary hyperplasia in transgenic mice expressing a human growth hormone-releasing factor gene. Molecular Endocrinology 2 606-612. (doi:10.1210/mend-2-7-606)

Naves LA, Daly AF, Dias LA, Yuan B, Zakir JC, Barra GB, Palmeira L, Villa C, Trivellin G, Junior AJ et al. 2015 Aggressive tumor growth and clinical evolution in a patient with X-linked acro-gigantism syndrome. Endocrine [in press]. (doi:10.1007/s12020-015-0804-6)

Rostomyan L, Daly AF, Petrossians P, Nachev E, Lila AR, Lecoq AL, Lecumberri B, Trivellin G, Salvatori R, Moraitis AG et al. 2015 Clinical and genetic characterization of pituitary gigantism: an international collaborative study in 208 patients. Endocrine-Related Cancer 22 745-757. (doi:10.1530/ERC-15-0320)

Saveanu A, Lavaque E, Gunz G, Barlier A, Kim S, Taylor JE, Culler MD, Enjalbert A \& Jaquet P 2002 Demonstration of enhanced potency of a chimeric somatostatin-dopamine molecule, BIM-23A387, in suppressing growth hormone and prolactin secretion from human pituitary somatotroph adenoma cells. Journal of Clinical Endocrinology and Metabolism 87 5545-5552. (doi:10.1210/jc.2002-020934)

Szalontay L, Schally AV, Popovics P, Vidaurre I, Krishan A, Zarandi M, Cai RZ, Klukovits A, Block NL \& Rick FG 2014 Novel GHRH antagonists suppress the growth of human malignant melanoma by restoring nuclear p27 function. Cell Cycle 13 2790-2797. (doi:10.4161/15384101. 2015.945879)

Torronteras R, Gracia-Navarro F \& Elsaesser F 1997 Control of growth hormone secretion from porcine fetal and neonatal pituitary tissue in vitro by growth hormone-releasing hormone, somatostatin, and insulin-like growth factor. Neuroendocrinology 65 117-128. (doi:10.1159/000127171)

Torronteras R, Canalejo A \& Elsaesser F 2012 Differential ontogenetic patterns of in vitro desensitization to GHRH in fetal and neonatal anterior pituitary. Neuroendocrinology 95 257-266. (doi:10.1159/ 000333779)

Trivellin G, Daly AF, Faucz FR, Yuan B, Rostomyan L, Larco DO, Schernthaner-Reiter MH, Szarek E, Leal LF, Caberg JH et al. 2014 Gigantism and acromegaly due to Xq26 microduplications and GPR101 mutation. New England Journal of Medicine 371 2363-2374. (doi:10.1056/NEJMoa1408028)

Received in the final form 4 December 2015

Accepted 15 December 2015

Made available online as an Accepted Preprint

15 December 2015
(C) 2016 Society for Endocrinology Printed in Great Britain
Published by Bioscientifica Ltd. 